\title{
Chantal Akerman: Tempo Expandido
}

Lucas Murari $^{1}$

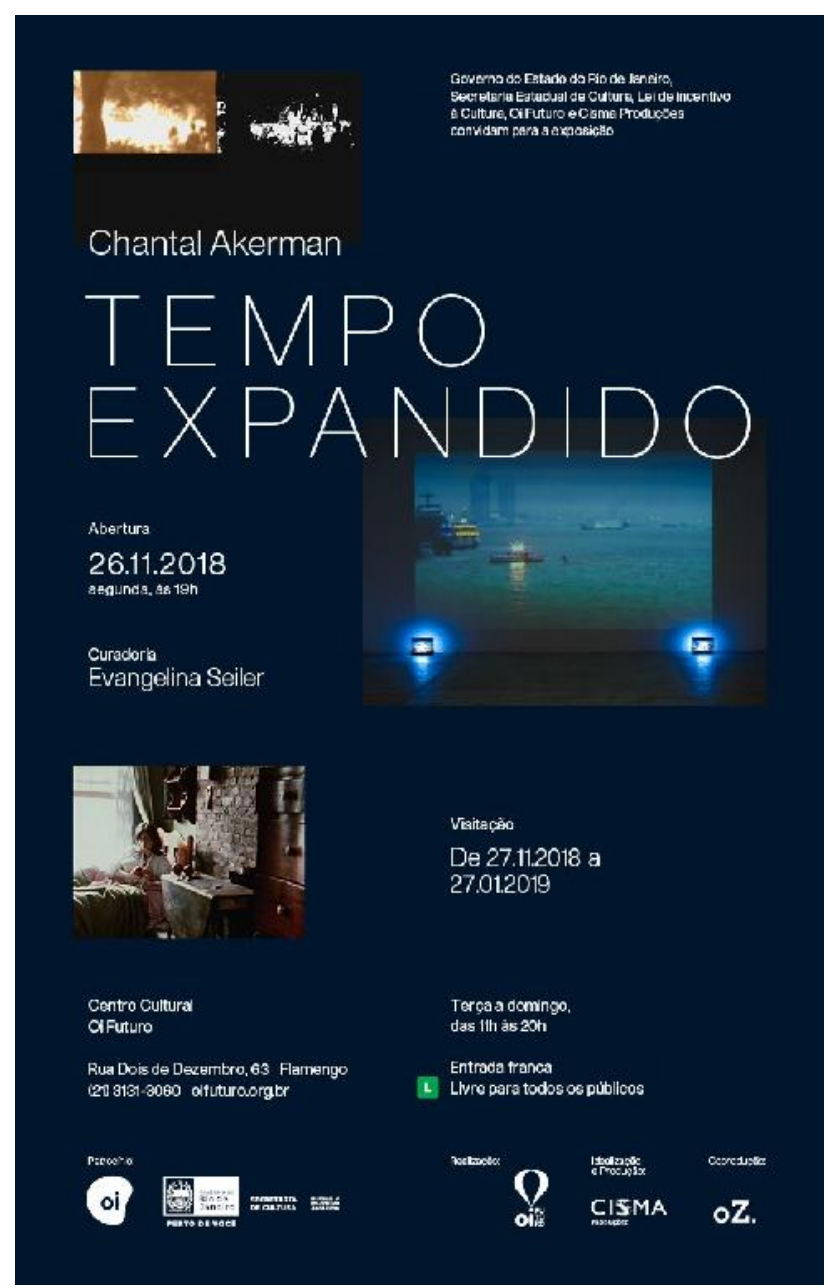

Figura 1: Cartaz da expoisção Chantal Akerman: Tempo Expandido, Centro Cultural Oi Futuro, de 27 de Novembro de 2018 a 27 de Janeiro de 2019 | (C) Centro Cultural Oi Futuro

Chantal Akerman: Tempo Expandido é o título da exposição realizada entre 26 de Novembro de 2018 a 27 de Janeiro de 2019 no Centro Cultural Oi Futuro (Rio de Janeiro) dedicada a artista e cineasta belga falecida em 2015. Akerman havia sido homenageada com uma grande retrospectiva pelo Centro Cultural Banco do Brasil (CCBB) em 2009, quando esteve presente no Brasil. O novo projeto, no entanto, mostrou suas obras no formato instalativo, tipo de exibição que

${ }^{1}$ Escola de Comunicação/Universidade Federal do Rio de Janeiro, CEP 22290-240 Rio de Janeiro, RJ, Brasil. 
marca suas últimas décadas de atividade artística. Ela começou a circular no meio das artes visuais ainda em 1995. Suas videoinstalações foram expostas em alguns dos principais eventos de arte contemporânea do mundo, como a Documenta (Kassel 2000) e a Bienal de Veneza (2001 e 2015). Alguns dos principais museus e galerias de arte, como o MALBA, o Centro Georges Pompidou, a Ambika P3 e a Marian Goodman, também apresentaram suas obras nesse formato. Essa foi a primeira exposição consagrada a artista no Brasil nessa configuração específica.

O nome escolhido para a exposição no Oi Futuro - Tempo Expandido - condensa um dos principais conteúdos poéticos presentes em sua vasta filmografia. A obra de Akerman é marcada pela exploração conceitual do tempo. A esgarçamento das ações diegéticas, a dilatação dos planos e a consequente reconfiguração do ritmo cinematográfico, são alguns dos elementos responsáveis por embaralhar a sequencialidade cronológica. Os cinco trabalhos selecionados pela curadora Evangelina Seiler caminham nesse sentido. O tempo se torna o atributo essencial para a percepção sensível proposta pela cineasta belga. Ela explorou gêneros que transitam entre o documentário e a ficção, mas com toques de experimentação da linguagem que tornaram seu estilo bastante no singular tanto no meio cinematográfico, quanto no contexto das artes visuais. A própria presença de Chantal Akerman - também presente no título da exposição - é fundamental em suas criações. A artista é a figura central em várias das instalações; ou ainda as narrativas fílmicas são fortemente autobiográficas.

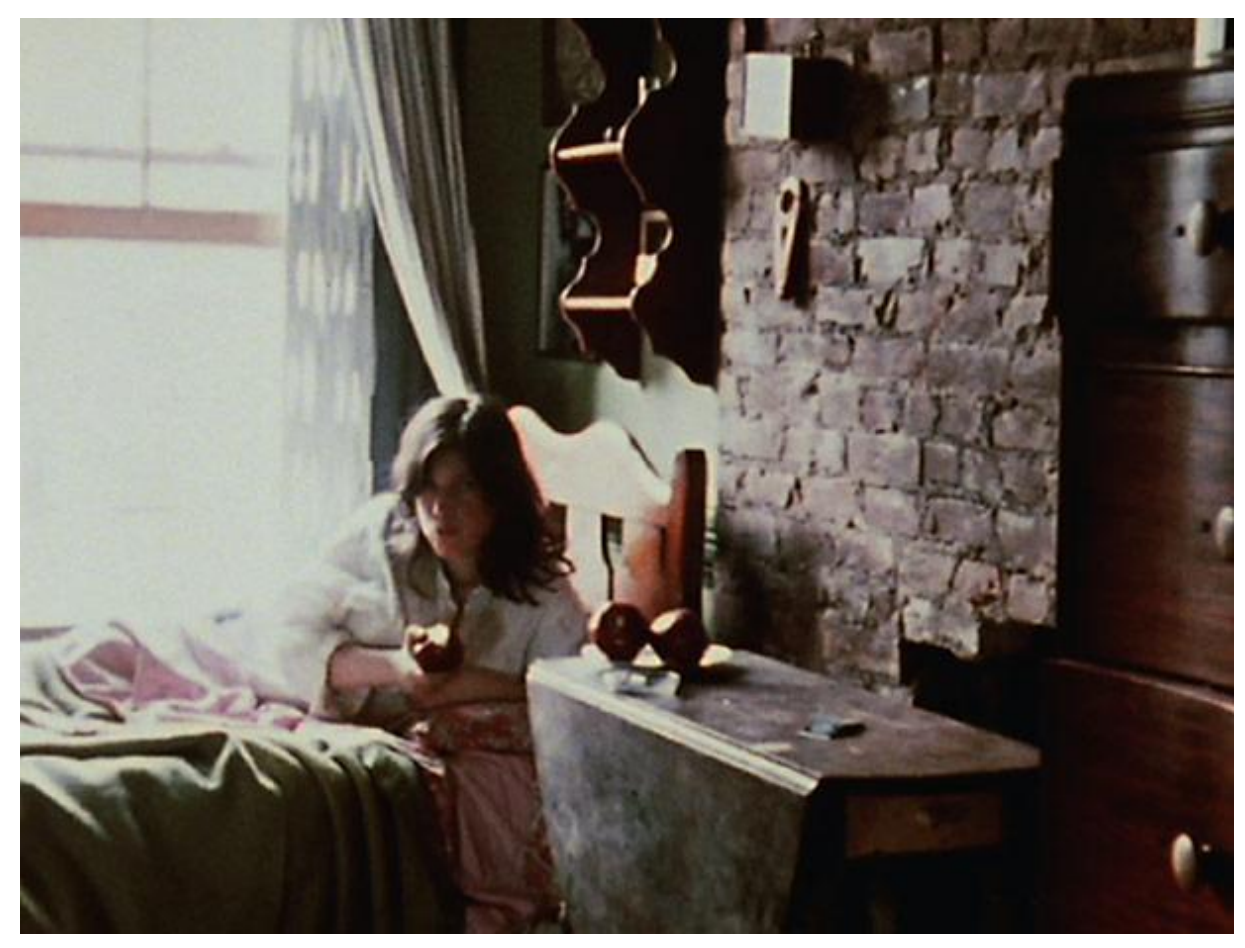

Figura 2: instalação com fotograma de O Quarto (La Chambre, 1972-2007), de Chantal Akerman | ( ) Centro Cultural Oi Futuro 
A primeira sala da exposição, que ocupou três andares do Centro Cultural, foi dedicada a duas obras, exibidas em loop: $O$ quarto (La Chambre), realizado originalmente em 1972; e Anoitecer em Xangai (Tombée de nuit sur Shangai), de 2009, feito para o longametragem coletivo ${ }^{2} O$ Estado do Mundo (2007). O primeiro é composto por um longo plano-sequência executando um movimento panorâmico em torno de um quarto residencial. A própria Chantal Akerman é vista sentada em uma cama. A câmera mostra ainda outros objetos que compõem o espaço: uma pequena mesa, uma escrivaninha, armários, o fogão e a chaleira. Tudo é filmado como se fosse uma espécie de natureza-morta. A própria personagem tem em mãos e depois come um dos elementos mais icônicos desse imaginário visual, uma maçã. A protagonista interpela a câmera diretamente (Figura 2). O quarto é um autorretrato silencioso e misterioso, criado a partir de um dos ambientes mais simbólicos presentes em sua trajetória artística ${ }^{3}$. Foi filmado logo depois de sua mudança da Bélgica (Bruxelas) para os Estados Unidos (Nova Iorque). O novo tratamento desse filme como videoinstalação foi feito em 2012. Anoitecer em Xangai, um de seus últimos trabalhos, possui ecos dessa estética da natureza-morta. Esse, no entanto, é composto por vistas de uma megalópole oriental. $\mathrm{O}$ gesto observacional proposto pela artista privilegia o início da noite na cidade. Essa contemplação deflagra as muitas ações e objetos que integram o espaço eleito: o porto, os barcos, os transeuntes, os gigantescos anúncios publicitários presentes nos arranha-céus. A videoinstalação não possui enredo. Aqui o protagonista é Xangai, e não mais um sujeito, como em uma espécie de atualização das Sinfonias das Cidades tão marcantes ao longo da história do cinema. O modo como foi organizado a exposição colocou O Quarto e Anoitecer em Xangai em contraste. Por mais que ambos dialoguem com gêneros pictóricos, pode se dizer que são diametralmente opostos. O primeiro foi filmado no início de sua carreira, em película $16 \mathrm{~mm}$, num ambiente interior em rotação e totalmente controlado; o segundo é um projeto tardio, gravado com equipamento digital, com planos estáticos, em paisagens essencialmente urbanas e à mercê de acontecimentos imprevistos. O que os une é o esvaziamento narrativo e a percepção temporal explorada pelo conceito de Tempo Expandido enfatizado pela pesquisa curatorial. Claire Atherton, montadora que trabalhou em vários dos projetos de Akerman e que também atuou como assessora artística da exposição no Oi Futuro, ressaltou em entrevista a importância de mostrar tais obras no formato instalativo:

“(...) se tratando de instalações, há um diferencial. Quando editávamos filmes, colocávamos uma imagem após a outra. Quando passamos a trabalhar com instalações, começamos a colocar as imagens também ao lado uma da outra. Isso cria uma segunda

\footnotetext{
${ }^{2}$ Outros nomes que compuseram o filme são Ayisha Abraham, Apichatpong Weerasethakul, Pedro Costa, Vicente Ferraz e Wang Bing.

${ }^{3}$ A casa é um espaço de confinamento da mulher, que em muitas vezes não era permitida ter acesso a vida pública. Chantal Akerman explorou esse mote narrativo brilhantemente em Jeanne Dielman, 23, quai du commerce, 1080 Bruxelles (1975).
} 
dimensão e dá ainda mais espaço para o espectador, porque ele também tem um movimento a fazer" (Claire Atherton apud Pécora 2018)

O segundo andar da exposição foi composto por duas obras. Verão maníaco (Maniac summer, 2009) consiste em material audiovisual registrado a partir do apartamento de Chantal Akerman em Paris. A videoinstalação é um tríptico sem começo nem fim. A câmera está posicionada próxima a janela, com enquadramentos ora para o espaço exterior, ora para o interior do prédio. Observamos os movimentos tanto do parque em frente, como também os afazeres domésticos e profissionais de Akerman. Fragmentos do cotidiano da artista são apresentados em uma das partes do tríptico. Visitamos sua privacidade, conhecemos sua casa, o escritório onde trabalha, sua paisagem doméstica. Sons ambientes da rua e do apartamento se misturam para fornecer a trilha sonora. Verão maníaco foi o trabalho mais extenso selecionado nesse projeto (34'04" em loop). Separado por uma parede estava alocado Minha mãe ri, prelúdio (My Mother Laughs - Prelude, 2012), leitura de Chantal Akerman de trechos de seu livro homônimo publicado em 2013 ( $M a$ mère rit). A artista é vista sentada em um ambiente escuro diante das páginas do manuscrito. A publicação aborda a relação entre Chantal e sua mãe, Nelly Akerman. A configuração da cena reitera a importância da solidão da artista lendo o texto em torno sua mãe enferma. Para a cineasta: "Texto e imagens formam um todo que fala de doença, morte, amor, confinamento, homossexualidade, o oposto de homossexualidade, casamento, normas, pertencimento e não pertencimento" (Akerman 2018).

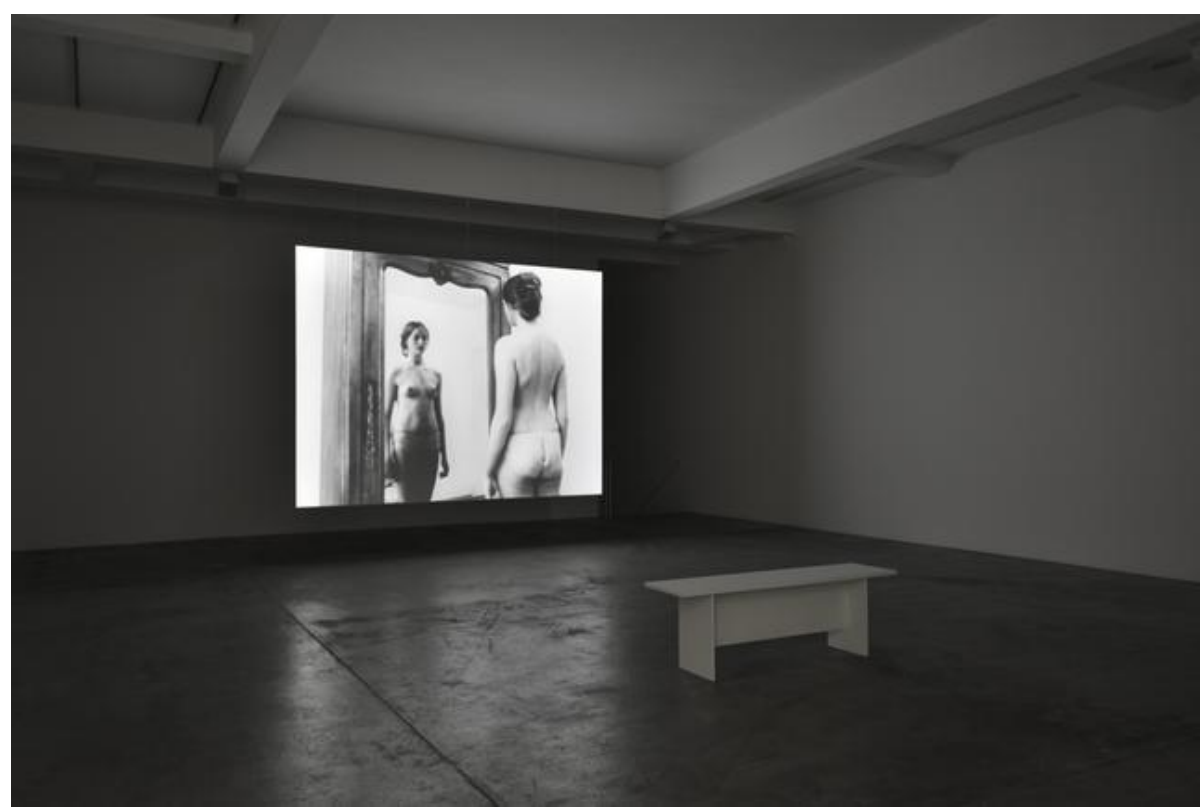

Figura 3: instalação com fotograma de No Espelho (In the mirror, 1971-2007), de Chantal Akerman | \C Centro Cultural Oi Futuro 
Por fim, a última sala é toda dedicada a obra No Espelho (In the Mirror). A instalação mostra uma cena a partir de um dos primeiros filmes realizados por Akeman - $A$ amada criança ou $\mathrm{Eu}$ toco para ser uma mulher casada (L'Enfant Aimé ou Je joue à être une femme mariée, 1971). Na figura 3 vemos uma jovem semi-nua, em frente a um espelho, observando minuciosamente seu próprio corpo refletido. O longo plano é acompanhado pela auto-descrição: "Sou pálida. Tenho sardas. Tenho uma boca bonita. Mal tenho cintura". A espacialidade joga com a posição da personagem. Por mais que a jovem esteja diante do espelho, ela também está de costas para a câmera e para o espectador, mas cujo reflexo também é possível ver. No Espelho é um retrato de uma mulher em sua intimidade. Por mais que o filme original seja do início da década de 1970, o recorte dessa cena só foi ser realizado em 2007, para ser exibido como videoinstalação em um projeto em torno da presença do corpo feminino na arte da década de 1970.

Para além da dimensão temporal e autobiográfica, a exposição no Centro Cultural Oi Futuro também enfatizou a importância da dimensão espacial presente na carreira de Chantal Akerman. Ambientes confinados, vistas de paisagens, enquadramentos reflexivos, permeiam as cinco videoinstalações. Algumas das obras são novos tratamentos de trabalhos anteriores, demonstrando assim como a sua poética é de uma riqueza ímpar na história da arte. Tendo concebido 42 filmes (entre curtas e longas-metragens), nove instalações e três livros, Akerman se tornou um dos nomes chaves da atividade artística realizada nas últimas décadas. Essa exposição apresentou um pequeno recorte dessa produção, em formato novo para o público brasileiro.

\section{BIBLIOGRAFIA}

Akerman, Chantal. 2018. My mother laughs, prelude. Material de divulgação. Rio de Janeiro: Oi Futuro.

Pécora, Luísa. 2018. "Entrevista: Claire Atherton sobre Chantal Akerman: 'Ela pertence a todos os lugares'”. http://mulhernocinema.com/destaques/claire-athertonsobre-chantal-akerman-ela-vive-no-mundo-e-pertence-atodos-os-lugares. (acesso em 06-VI-2019). 